\title{
Gas-Chromatographic Determination of the Trimethylsilyl Derivatives of Polyhydric Alcohol Humectants in Tobacco and in Tobacco Smoke*
}

\author{
by N. Carugno, S. Rossi and G. Lionetti \\ Laboratorio Chimico dei Monopoli di Stato, Rome, Italy
}

The determination of humectants in tobacco and in tobacco smoke, taking their large use in tobacco products into consideration, has been the subject of many publications.

Thin-layer chromatography has been applied by Wright to determine humectants in tobacco products which are also present in small quantities (I).

Laurene, Cundiff and Greene outlined a colorimetric method to analyse glycerol and propylene glycol in cigarette smoke (2).

The gas-chromatographic determination of glycerine and propylene glycol in tobacco has been described by Cundiff, Greene and Laurene (3) and it has been the subject of a collaborative study in the United States (4).

Some polyhydric alcohols have been analysed as their trimethylsilyl ether derivatives in tobacco by Slanski and Moshy (5). The conversion to TMS derivatives of polyols, in the gas-chromatographic method, has the advantage of a reduction in polarity and an increase in vapour pressure with a resulting decrease of analysis times and a more effective separation of chromatographic peaks.

This paper describes a method for the qualitative and quantitative analyses of polyhydric alcohols also in tobacco smoke and it shows the results of the combination of gas-chromatography with mass spectrometry for both humectants extracted from tobacco and smoke condensate in order to verify whether the interference of other silylated products occurs.

\section{EXPERIMENTAL}

\section{Apparatus and Operating Conditions}

The gas-chromatograph Carlo Erba Model C, equipped with a flame ionization detector and temperature programming, was used. The mass spectra were obtained on a Perkin Elmer gas-chromatograph mass spectrometer Mod. 270.

A stainless steel column, $3 \mathrm{~m}$ in length, i. d. $2 \mathrm{~mm}$,

\footnotetext{
* Presented at the 5th International Tobacco Scientific Congress, Hamburg, September 1970.
}

filled with $5 \%$ SE 30 on 60/80 mesh Chromosorb W was employed for all experiments. The chromatographic conditions used were: a) linear programmed temperature: $130^{\circ} \mathrm{C}$ for 17 minutes to $200^{\circ} \mathrm{C}$ at $2.5^{\circ} \mathrm{C} / \mathrm{min}$, injection temperature: $320^{\circ} \mathrm{C}$, detector temperature: $160^{\circ} \mathrm{C}$, carrier gas nitrogen at a flow rate of $40 \mathrm{ml} / \mathrm{min}, \mathrm{b}$ ) isothermal column temperature for the analysis of sorbitol: $200^{\circ} \mathrm{C}$, all other conditions were the same as those given above. The trimethylsilylation reagents used were trimethylchlorosilane and hexamethyldisilazane obtained from the Carlo Erba Company. In analyses by the mass spectrometer the ion source temperature was $150^{\circ} \mathrm{C}$, the energy of the bombarding electrons was kept at $70 \mathrm{eV}$ and the scanning speed was 30 decade/second.

\section{Procedure}

Tobacco products: $10 \mathrm{~g}$ of tobacco were extracted in a Soxhlet apparatus with $250 \mathrm{ml}$ methanol for $5 \mathrm{~h}$. The methanol solution was quantitatively transferred to a $250 \mathrm{ml}$ volumetric flask and made up to volume. 25 milliliters of this solution were evaporated by a dry nitrogen stream and $0.8 \mathrm{ml}$ pyridine, $0.8 \mathrm{ml}$ hexamethyldisilazane and $0.4 \mathrm{ml}$ trimethylchlorosilane were added to the residue. After being thoroughly stirred for zo seconds, the mixture was left to settle for 10 minutes and then centrifuged. Two microliters of this solution were injected into the gas-chromatograph. As for sorbitol, the extraction method with methanol gave a recovery not exceeding $38 \%$. For this reason, other solvents such as pyridine and acetone were used. The best result was obtained by the latter.

Tobacco smoke: 20 plain cigarettes, previously selected with regard to both weight and pressure drop, were smoked according to CORESTA Standard Procedure. The condensate was collected in an electrostatic smoke trap and removed from there with $100 \mathrm{ml}$ of methanol. The solution was evaporated by a dry nitrogen stream and the residue treated as previously outlined.

The tobacco samples and the relevant cigarettes required for the analyses were prepared by adding a mixture of glycerine, diethyleneglycol, propylene glycol, triethylene glycol, $\mathrm{I}_{-3}$ butylene glycol and sorbitol to the extent of ${ }_{1} \%$ for each single humectant. 


\section{RESULTS AND DISCUSSION}

A synthetic mixture of pure polyols was prepared and converted to their TMS: their separation is shown in Fig. 1. When working at the temperature programmed under the above-mentioned conditions, a good separation is obtained of the peaks corresponding to propylene glycol [1], 1-3 butylene glycol [2], diethylene glycol [3], glycerine [4] and triethylene glycol [5], while for sorbitol it is advisable to operate in isotherm at $200^{\circ} \mathrm{C}$ (Fig. 2).

Figure 1. Gas-chromatogram of pure TMS-glycols.

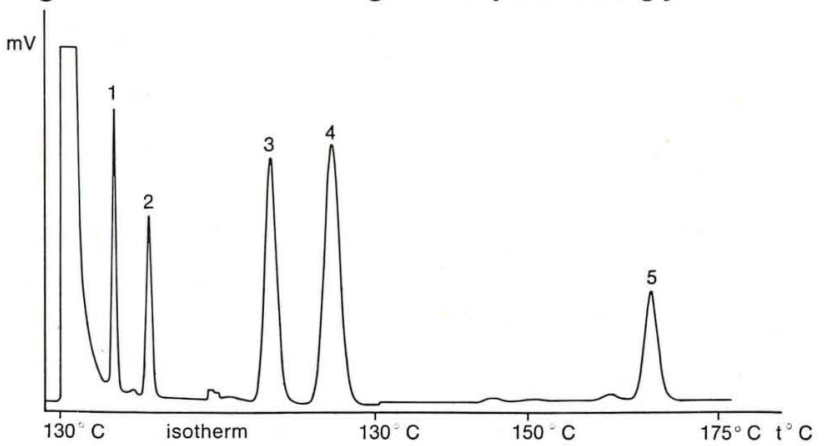

Figure 2. Gas-chromatogram of pure TMS-sorbitol.

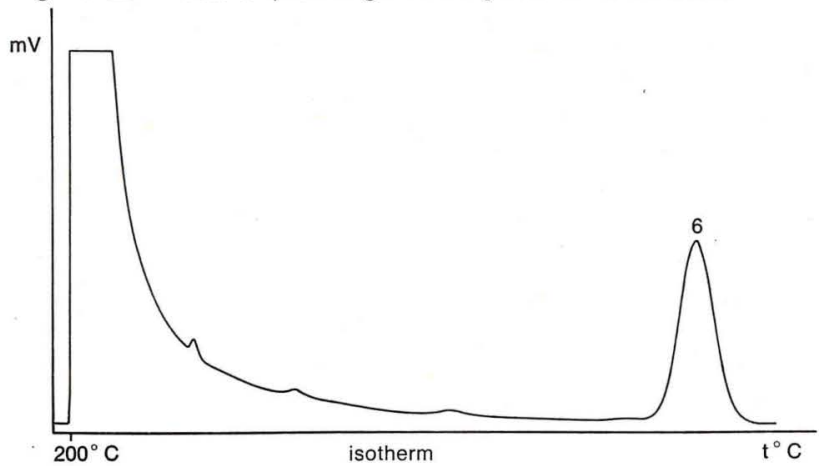

In Figures 3 and 4 two chromatograms are shown of an extract obtained from tobacco containing no humectants and an extract from the same tobacco to which had been added six polyhydric alcohols, while Fig. 6 shows the chromatogram of TMS sorbitol extracted from tobacco. Though the comparison of both chromatograms already shows that no other silylated compound present in the solution interferes, this result was nevertheless verified by making mass spectra for each peak.

In the scientific literature $(6,7,8)$ the mass spectra of trimethylsilyl derivatives of some glycols are set forth;
Figure 3. Gas-chromatogram of an extract of tobacco.

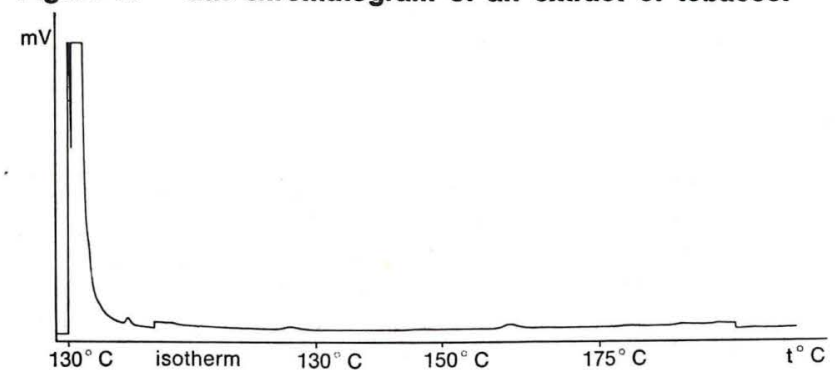

Figure 4. Gas-chromatogram of TMS-glycols extracted from tobacco.

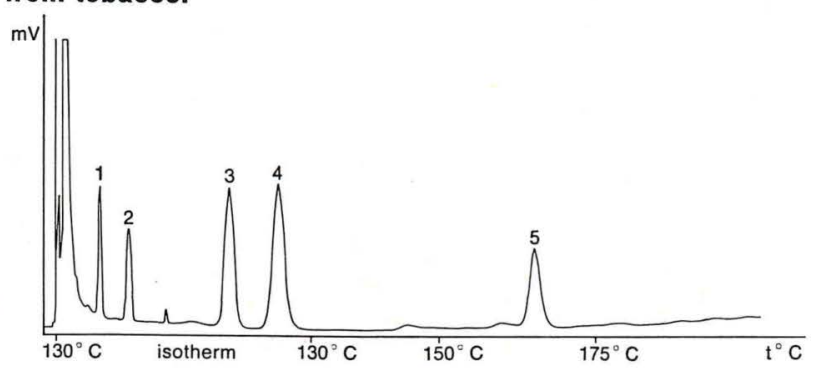

Figure 6. Gas-chromatogram of TMS-sorbitol extracted from tobacco.

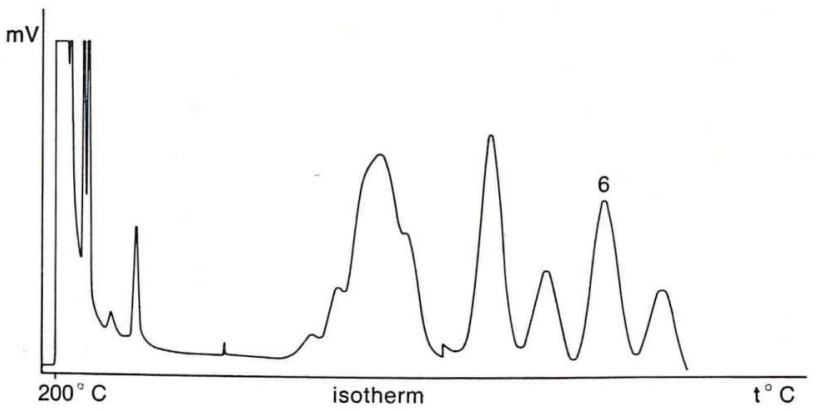

however, for each of the six humectants under examination the mass spectra were made starting from completely pure products. The mass spectra relative to the chromatographic peaks correspond to those of pure polyols. Fig. 7 shows, for example, the two spectra of diethylene glycol and Fig. 8 shows the two sorbitol spectra. Hence, the combination of gas-chromatography and mass spectrometry made it possible to confirm that the gas-chromatographic determination of polyhydric alcohols in tobacco by the silylation method is an accurate and quick procedure with a fair reproducibility and that it can also be used for mixtures of different humectants. As to the completeness of the extraction, it was found that the recovery of added glycols ranges

Figure 7. a) Mass spectra of pure TMS-diethylene glycol, b) mass spectra of TMS-diethylene glycol extracted from tobacco.

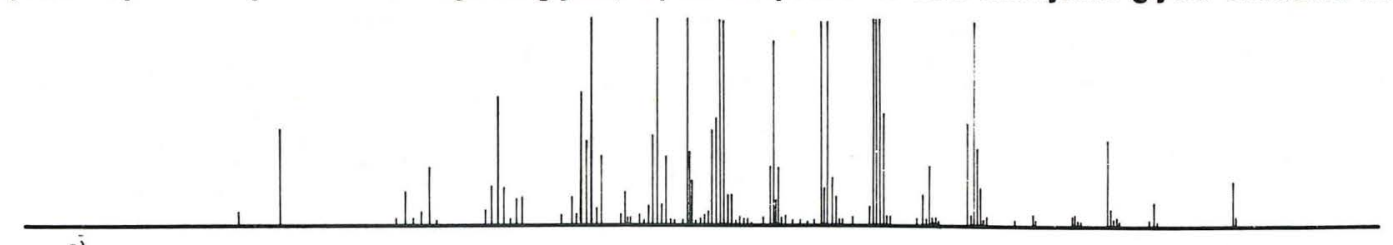

a)

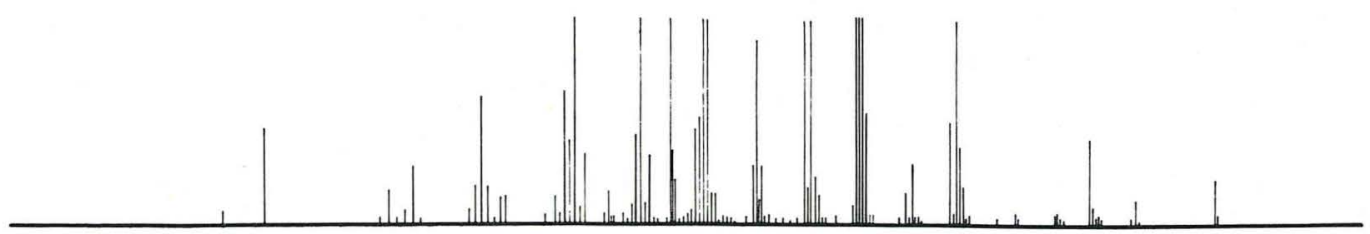


Figure 8. a) Mass spectra of pure TMS-sorbitol, b) mass spectra of TMS-sorbitol extracted from tobacco.

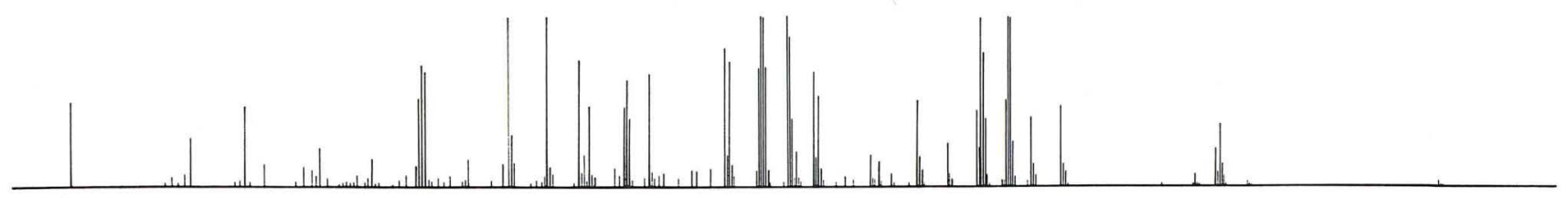

a)

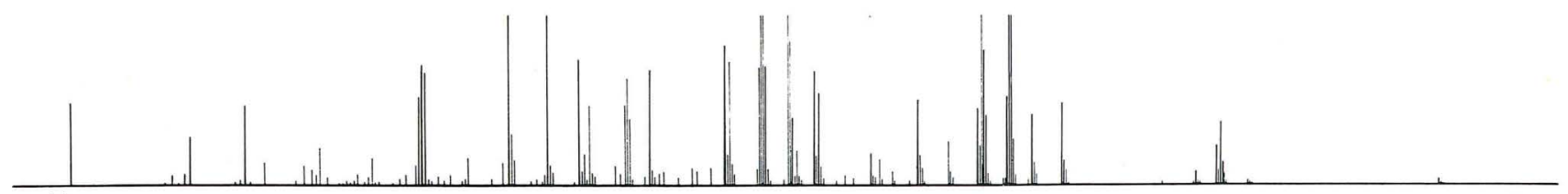

b)

from 95 to $104 \%$ as regards propylene glycol, $1-3$ butylene glycol, diethylene glycol, glycerine, triethylene glycol, while for sorbitol this recovery was $86 \%$. Table I shows the average values of recovery in the six humectants:

Table 1. Recovery of added polyols in tobacco.

\begin{tabular}{l|c}
\hline \multicolumn{1}{c|}{ Humectant added } & Recovery $(\%)$ \\
\hline [1] Propylene glycol & 97.8 \\
[2] 1-3 Butylene glycol & 98.1 \\
[3] Diethylene glycol & 97.5 \\
[4] Glycerine & 98.6 \\
[5] Triethylene glycol & 99.0 \\
[6] Sorbitol & 86.0 \\
\hline
\end{tabular}

The gas-chromatographic determination of humectants in cigarette smoke involves more complicated problems compared to tobacco, because there are a larger number of compounds present which are silylated and detected under the operating chromatographic conditions.

Figure 9. Gas-chromatogram of an extract of tobacco smoke.

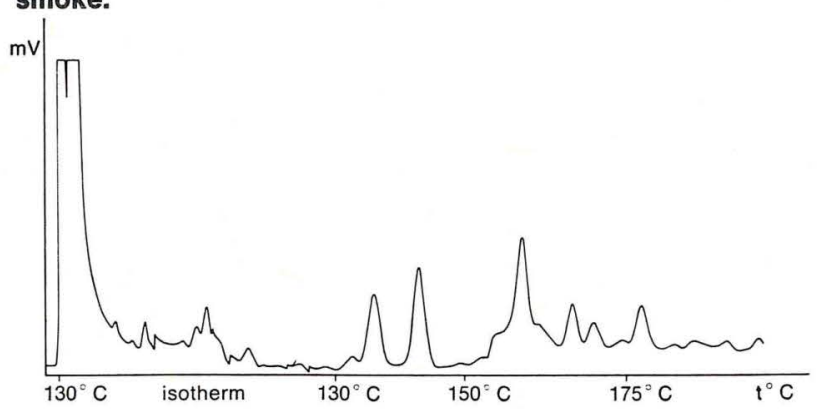

Figures 9 and to show two chromatograms, the former of which refers to cigarette smoke obtained from tobacco with no humectants and the latter to the smoke of cigarettes manufactured with the same tobacco to which were added six glycols. Of these, a good separation with no interference was obtained for propylene glycol [1], 1-3 butylene glycol [2], diethylene glycol [3], glycerine [4], while the peak of triethylene glycol [5] superimposed another peak which at first was thought to correspond to a compound having the same retention time. However, the mass spectrum relative to the peak of triethylene glycol perfectly corresponds to that of the standard product, whence one could infer that tobacco smoke with no humectant contains triethylene glycol.

The first mass spectra show that the gas-chromatographic method for the determination of polyhydric alcohols as trimethylsilyl derivatives can be extended also to cigarette smoke, though additional studies are still required to develop a definite procedure in order to study the optimum conditions for the determination of all the five glycols under examination. In Figures 11 ,

Figure 10. Gas-chromatogram of TMS-glycols extracted from tobacco smoke.

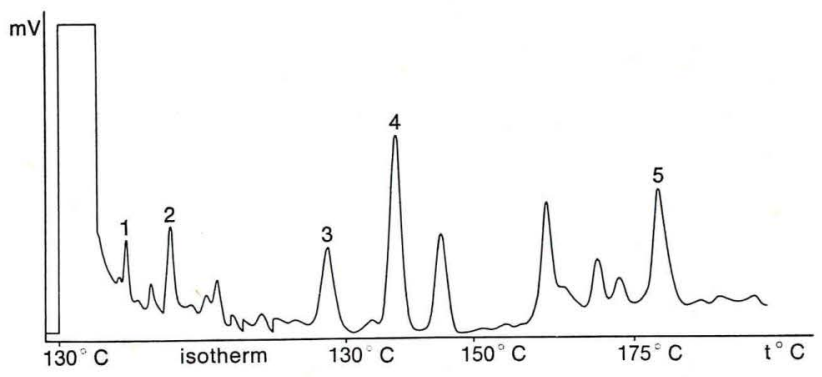

Figure 11. a) Mass spectra of pure TMS-glycerine, b) mass spectra of TMS-glycerine extracted from tobacco smoke.

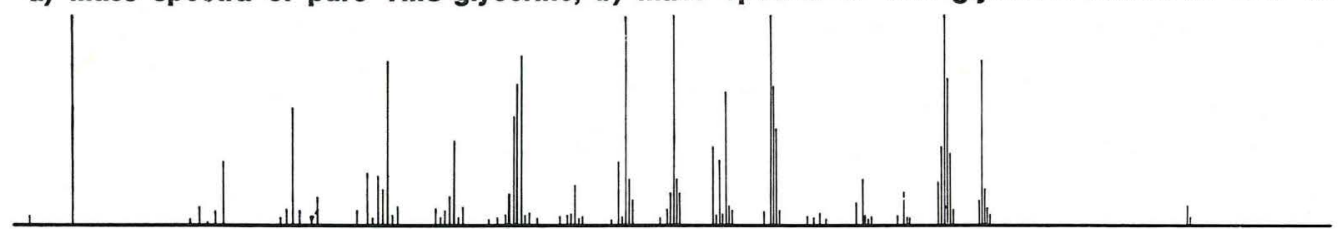

a)

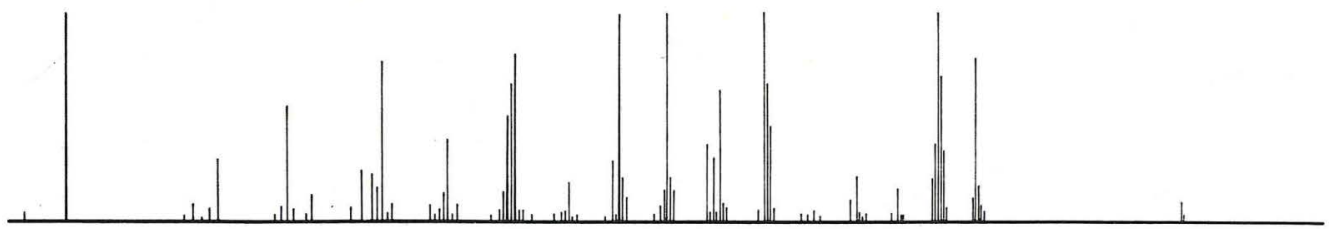

b) 
Figure 12. a) Mass spectra of pure TMS-butylene glycol, b) mass spectra of TMS-butylene glycol extracted from tobacco smoke.

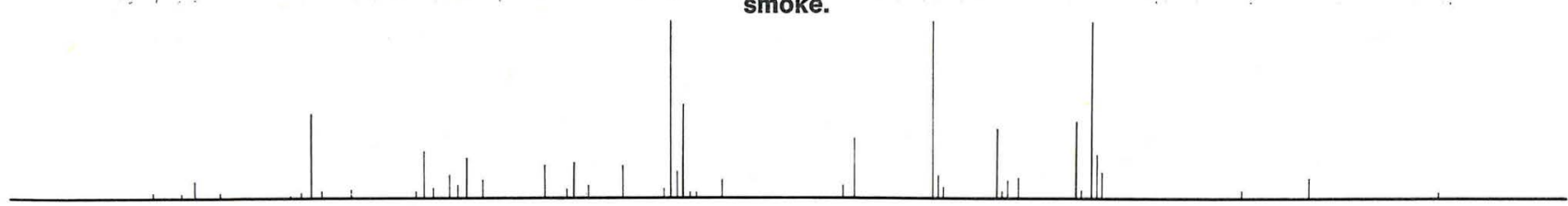

a)

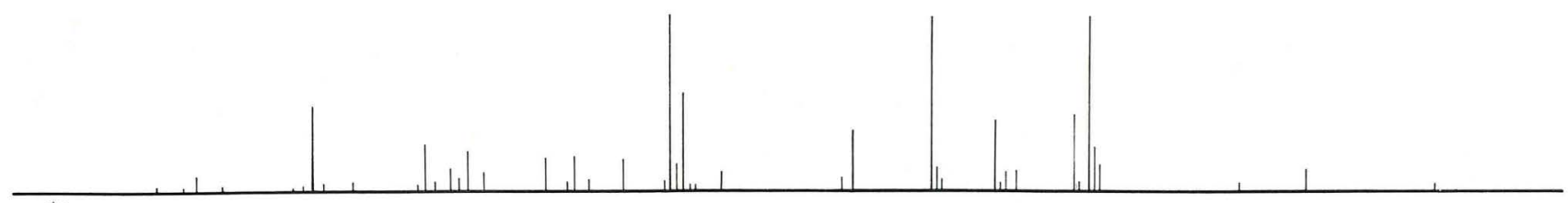

b)

Figure 13. a) Mass spectra of pure TMS-triethylene glycol, b) mass spectra of TMS-triethylene glycol extracted from tobacco smoke.

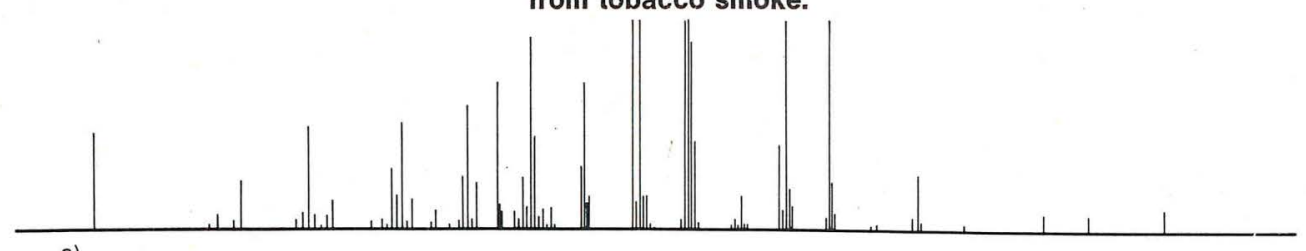

a)

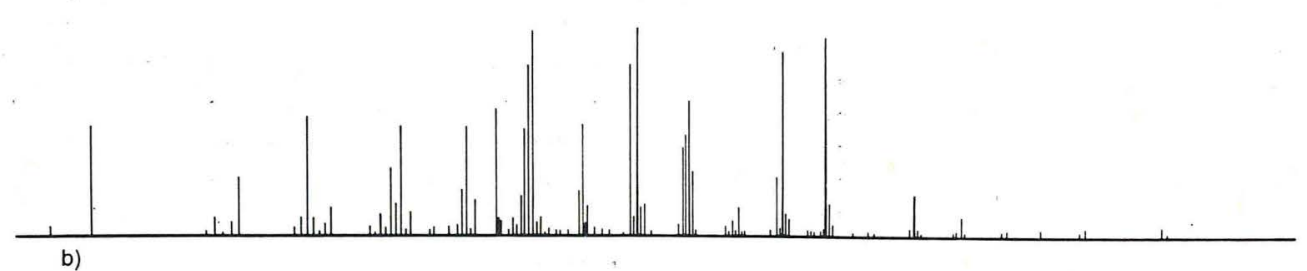

b)

I2 and 13 the mass spectra of glycerine, butylene glycol and triethylene glycol are shown.

As for the quantitative determination of humectants in both tobacco and smoke, the calibration curve was obtained for each glycol.

\section{SUMMARY}

A qualitative and quantitative procedure has been developed for the determination of humectants in manufactured tobacco by gas-chromatographic method with a flame ionization detector. It consists of extraction with methanol, concentration of the extract and treatment with Tri-Sil reagents. The operating gas-chromatographic conditions are set forth.

Samples of tobacco containing glycerine, propylene glycol, diethylene glycol, triethylene glycol, I-3 butylene glycol and sorbitol have been analyzed with recoveries, for the first five ones, in the range of 95-104\%.

In order to verify that each chromatographic peak corresponded to the relative glycol, with no interference by other silylated compounds, the mass spectra were obtained through the combination of gas-chromatography with mass spectrometry. The results achieved confirm, as far as tobacco is concerned, that the procedure is accurate and precise.

The same method for the determination of humectants was extended to cigarette smoke. Even though this involves more complicated problems, as compared to tobacco, because of the presence of silylated com- pounds, it was found that, for certain glycols, the gaschromatography of the trimethyl derivatives can be also used as a method of analysis.

The mass spectra of some polyhydric alcohols are shown.

\section{RESUME}

On a mis au point un procédé pour la détermination qualitative et quantitative des humectants dans le tabac manufacturé par la méthode de la chromatographie en phase gazeuse. Il consiste en une extraction avec méthanol, suivie par la concentration de l'extrait et par le traitement avec des réactifs Tri-Sil. On décrit les conditions opératoires de la chromatographie en phase gazeuse.

On a analysé des échantillons de tabac contenant glycérine, diéthylène glycol, propylène glycol, triéthylène glycol, 1-3-butylène glycol et sorbitol, avec des récupérations, pour les cinq premiers, comprises entre 95 et $104 \%$.

Pour vérifier si chaque pic chromatographique correspondait au glycol considéré sans interférence d'autres composés silanisés, on a effectué les spectres de masse en utilisant la combinaison de la chromatographie en phase gazeuse et de la spectroscopie de masse. Les résultats obtenus prouvent, quant au tabac, que ce procédé est précis et exact.

Cette méthode de détermination des humectants a été étendue à la fumée de cigarette. Bien qu'elle implique des problèmes encore plus complexes que pour le 
tabac, du fait de la présence d'une plus grande quantité de composés silanisés, on a vérifié que pour certains glycols la chromatographie en phase gazeuse des dérivés triméthylsilyl peut être employée comme méthode d'analyse.

On présente les spectres de masse de certains polyalcools.

\section{ZUSAMMENFASSUNG}

Für die quantitative und qualitative Bestimmung von Feuchthaltemitteln in verarbeitetem Tabak wurde eine Nachweismethode mit einer Kombination von Gaschromatographie und dem Einsatz eines Flammenionisations-Detektors entwickelt. Das Verfahren beruht auf der Extraktion mit Methanol und auf einer Anreicherung des Extraktes und einer Behandlung mit Tri-SilReagenzien. Die Bedingungen der Gaschromatographie werden beschrieben.

Tabakproben, die Glyzerin, Propylenglykol, Diäthylenglykol, Triäthylenglykol, 1-3-Butylenglykol und Sorbitol enthalten, wurden untersucht. Die Ausbeuten lagen zwischen $95 \%$ und $104 \%$.

Um zu prüfen, ob jeder Peak der Chromatogramme eindeutig dem jeweiligen Glykol entspricht und nicht durch andere silylierte Verbindungen beeinträchtigt wird, wurden die entsprechenden Massenspektren mit Hilfe der Kombination von Gaschromatographie und Massenspektrometrie hergestellt. Die Methode ist für die Analyse von Tabak fehlerfrei und genau.

Das beschriebene Verfahren für die Bestimmung von Feuchthaltemitteln wurde auch für die Untersuchung von Cigarettenrauch angewendet. Obwohl die Untersuchung des Rauches im Vergleich zu der des Tabaks durch das Vorkommen einer größeren Zahl silylierter Verbindungen komplizierter ist, wurde festgestellt, daß sich die gaschromatographische Bestimmung der Trimethyl-Derivate als Analysenmethode für einige Glykole eignet.

Die Massenspektren einiger mehrwertiger Alkohole werden gezeigt.

\section{REFERENCES}

1. Wright, J.: Chemistry and Industry 1963, 1125.

2. Laurene, A. H., Cundiff, R. H., and Greene, G. H.: Tobacco Science 9 (1.965) I.

3. Cundiff, R. H., Greene, G. H., and Laurene, A. H.: Tobacco Science 8 (I964) I63.

4. Giles, J. A., and Cundiff, R. H.: Journal of the AOAC 52 (1969) 753.

5. Slanski, J. M., and Moshy, R. J.: Journal of Chromatography 35 (1968) 94.

6. Sharkey, A. S., Jr., Friedel, R. A., and Langer, S. H.: Anal. Chem. 29 (1957) 770.

7. Diekman, J., Thomson, J. B., and Djerassi, C.: J. Org. Chem. 33 (1968) 2271.

8. Golding, B. T., Rickards, R. W., and Barber, M.: Tetrahedron Letters 1964, 2615.

The authors' address:

Laboratorio Chimico, Monopoli di Stato, Piazza Mastai 11, Rome, Italy. 